\title{
Molecular Typing of $S$-alleles through Identification, Characterization and cDNA Cloning for $S$-RNases in Sweet Cherry
}

\author{
Ryutaro Tao, ${ }^{1}$ Hisayo Yamane, and Akira Sugiura \\ Laboratory of Pomology, Graduate School of Agriculture, Kyoto University, Kyoto 606-8502, Japan \\ Hideki Murayama \\ Faculty of Agriculture, Yamagata University, Tsuruoka 997-8555, Japan \\ Hidenori Sassa \\ Kihara Institute for Biological Research, Yokohama City University, Yokohama 244-0813, Japan \\ Hitoshi Mori \\ Graduate School of Bioagricultural Science, Nagoya University, Nagoya 464-8601, Japan
}

\begin{abstract}
AdDitional INDEX wORDs. gametophytic self-incompatibility, genomic DNA blot analysis, PCR, Prunus avium, RNA blot analysis, Rosaceae

Abstract. This report identifies $S$-RNases of sweet cherry (Prunus avium L.) and presents information about cDNA sequences encoding the $S$-RNases, which leads to the development of a molecular typing system for $S$-alleles in this fruit tree species. Stylar proteins of sweet cherry were surveyed by two dimensional polyaclylamide gel electrophoresis (2DPAGE) to identify $S$-proteins associated with gametophytic self-incompatibility. Glycoprotein spots linked to $S$-alleles were found in a group of proteins which had $M r$ and $\mathrm{pI}$ similar to those of other rosaceous $S$-RNases. These glycoproteins were present at highest concentration in the upper segment of the mature style and shared immunological characteristics and $N$-terminal sequences with those of $S$-RNases of other plant species. cDNAs encoding these glycoproteins were cloned based on the N-terminal sequences. Genomic DNA and RNA blot analyses and deduced amino acid sequences indicated that the cDNAs encode $S$-RNases; thus the $S$-proteins identified by 2D-PAGE are $S$-RNases. Although $S^{l}$ to $S^{6}$-alleles of sweet cherry cultivars could be distinguished from each other with the genomic DNA blot analysis, a much simpler method of PCR-based typing system was developed for the six $S$-alleles based on the DNA sequence data obtained from the cDNAs encoding $S$-RNases.
\end{abstract}

Sweet cherry (Prunus avium L.) exhibits the monofactorial gametophytic self-incompatibility system similar to other selfincompatible fruit tree species of the Rosaceae. This system is controlled by a single locus, the $S$-locus, with multiple alleles (Tehrani and Brown, 1992). In this type of self-incompatibility, growth of a pollen tube bearing either one of the two $S$-alleles carried by the recipient pistil is arrested in the style (de Nettancourt, 1977).

The molecular mechanisms of the monofactorial gametophytic self-incompatibility have been extensively studied in solanaceous plant species. The $S$-gene products in pistils of Solanaceae are highly basic glycoproteins (Anderson et al., 1986; McClure et al., 1989) containing sequence motifs characteristic of the active site of the fungal RNases T2 (Kawata et al., 1988) and Rh (Horiuchi et al., 1988). Later, RNase activity was shown to be essential for the pollen rejection response (Huang et al., 1994; Royo et al., 1994). $S$-RNases alone are sufficient for determining the pollen rejection response in the gametophytic self-incompatibility system in the style of the Solanaceae (Lee et al., 1994; Murfett et al., 1994). Recently, $S$-RNases have also been shown

\footnotetext{
Received for publication 17 Aug. 1998. Accepted for publication 13 Jan. 1999. This work was partially supported by grant-in-aid no. 09460018 for Scientific Research (B) to R. Tao from the Ministry of Education, Science, Sports and Culture, Japan. We thank Yamagata Prefectural Horticultural Experiment Station and Fruit Tree Research Station of the Ministry of Agriculture, Forestry, and Fisheries of Japan for providing us with plant materials. We also thank H. Hirano of Yokohama City University for his helpful discussion and advice. The cost of publishing this paper was defrayed in part by the payment of page charges. Under postal regulations, this paper therefore must be hereby marked advertisement solely to indicate this fact. ${ }^{1}$ To whom reprint requests should be addressed; e-mail rtao@kais.kyoto-u.ac.jp.
}

to be involved in the monofactorial gametophytic self-incompatibility of almond [Prunus dulcis (Mill.) D.A. Webb] (Tao et al., 1997), apple (Malus $\times$ domestica Borkh.) (Janssens et al., 1995; Sassa et al., 1996), Japanese pear (Pyrus pyrifolia Nakai, synonym of Pyrus serotina Rehd.) (Norioka et al., 1996; Sassa et al., 1993, 1996), and European pear (Pyrus communis L.) (Tomimoto et al., 1996).

Most sweet cherry cultivars are self-incompatible and unable to bear fruit parthenocarpically; therefore, they will not set fruit unless pollinated with cultivars with different $S$-genotypes. In commercial orchards, cross-compatible cultivars that belong to different pollen incompatibility groups and flower simultaneously must be interplanted to ensure fruit set. Thus, determination of correct pollen incompatibility groups and assignment of cultivars to the groups are essential for good crop production.

Pollen incompatibility groups in sweet cherry have been identified by controlled pollination tests and/or pollen tube growth tests. Thus far, six different $S$-alleles and 13 incompatibility groups (Group I to XIII) and universal donor (Group O) have been identified (Knight, 1969; Tehrani and Brown, 1992). Although the six different $S$-alleles theoretically give 15 different incompatibility groups, only 13 of them have been identified; partly because pollination and pollen tube growth tests are time-consuming and prone to be affected by environmental factors.

Recently, Boskovic and Tobutt (1996) found a correlation between stylar RNase zymograms and $S$-alleles of sweet cherry, which lead to the development of $S$-genotype determination methods based on biochemical analysis (Boskovic et al., 1997). Although the technique is simple, it is unclear whether the RNase 
activities they found are true $S$-allelic products. Furthermore, styles are needed for the zymogram analysis, and $S$-genotypes can be determined only when styles are available. A DNA-based technology such as allele-specific PCR for apple $S$-alleles (Janssens et al., 1995) would be preferable. As opposed to the zymogram analysis, vegetative tissues can be used for a DNA-based analysis and $S$-genotypes can be determined for immature seedlings before flowering age.

In this study, we analyzed stylar proteins of sweet cherry by 2D-PAGE and identified glycoproteins associated with $S$-alleles. In terms of $M r$, pI values, immunological characteristics, and $\mathrm{N}$ terminal amino acid sequences, the glycoproteins were suggested to be $S$-RNases of sweet cherry. We also cloned cDNA for the glycoproteins. The deduced amino acid sequences from the cDNAs further confirmed that the proteins were $S$-RNases. By using oligonucleotide primers designed from the cDNA sequences, a PCR-based molecular typing system was developed for the six $S$ alleles, $S^{l}$ to $S^{6}$, of sweet cherry cultivars.

\section{Materials and Methods}

Plant material. Fifteen self-incompatible sweet cherry cultivars with known $S$-genotypes, representing seven incompatibility groups, and self-compatible 'Compact Stella' were used in this study (Table 1). 'Compact Stella' $\left(S^{3} S^{4 m}\right)$ (Lapins, 1975) originated as a mutant with semidwarf growth habit through X-ray irradiation of dormant scions of self-compatible 'Stella' $\left(S^{3} S^{4 m}\right)$ cherry (Lapins, 1970). 'Compact Stella' expresses a loss of the $S^{4}$ allele, one of the two $S$-alleles, in the pollen, but not in the style. Thus 'Compact Stella' is a universal pollinator but rejects both $S^{3}$ and $S^{4}$-pollen tube growth in the style (Lapins, 1975).

Protein assay. Styles with stigmas of all the cultivars listed in Table 1 were dissected from the flower buds at the balloon stage of development. For 'Satonishiki', styles with stigmas from the flower buds at different stages of development were also used. In addition, the upper, middle, and lower portions of the styles dissected from the flower buds of 'Satonishiki' at the balloon stage of development were used for the experiment. These samples were crushed in pre-chilled acetone $\left(-20^{\circ} \mathrm{C}\right)$ containing $8 \%(\mathrm{~m} /$ v) trichloroacetic acid plus $0.07 \%(\mathrm{v} / \mathrm{v}) 2$-mercaptoethanol, and incubated for $30 \mathrm{~min}$ at $-20^{\circ} \mathrm{C}$. The suspension was centrifuged at $10,000 g_{\mathrm{n}}$ for $10 \mathrm{~min}$, and the pellet was resuspended in acetone containing $0.07 \%(\mathrm{v} / \mathrm{v}) 2$-mercaptoethanol and incubated $1 \mathrm{~h}$ at $20^{\circ} \mathrm{C}$. After centrifugation at $10,000 g_{\mathrm{n}}$ for $10 \mathrm{~min}$, the supernatant was discarded and the pellet was dried under vacuum. Crude extracts were prepared from the acetone powder and subjected to 2D-PAGE using nonequilibrium $\mathrm{pH}$ gradient electrophoresis (NEPHGE) for the first dimension and SDS-PAGE for the second dimension as previously reported (Tao et al., 1997). After electrophoresis, proteins in the gel were detected by silver staining. For 'Satonishiki', proteins separated by 2D-PAGE were also electroblotted onto PVDF membrane and glycoproteins were detected with biotin-conjugated concanavalin A and horseradish peroxidase-conjugated streptavidin. Peroxidase activity on the membrane was visualized using 4-chloro-1-naphthol as a substrate. Immunodetection of proteins electroblotted onto PVDF membrane was also conducted for 'Satonishiki' and 'Velvet' by using the mouse anti- $S^{4}$-serum prepared against purified $S^{4}$ glycoprotein of Japanese pear (Sassa et al., 1993) as described previously (Tao et al., 1997). In addition, for these cultivars, portions of the PVDF membrane carrying the proteins of interest were also cut out after Coomassie Blue staining and subjected to a gas-phase protein sequencer (476A, Applied Biosystems, To-
Table 1 . Sweet cherry cultivars used and their S-genotypes.

\begin{tabular}{lcl}
\hline \hline IG $^{\mathrm{z}}$ & $S$-genotype & Cultivar \\
\hline I & $S^{1} S^{2}$ & Early Rivers \\
II & $S^{1} S^{3}$ & Gil Peck, Van \\
III & $S^{3} S^{4}$ & Bing, Royal Ann \\
IV & $S^{2} S^{3}$ & Velvet, Victor, Sue \\
VI & $S^{3} S^{6}$ & Governer Wood, Nanyo, Satonishiki \\
VII & $S^{3} S^{5}$ & Burlat, Moreau \\
$?$ & $S^{2} S^{x}$ & Peggy Rivers \\
IX & $S^{1} S^{4}$ & Rainer \\
None & $S^{3} S^{4 m}$ & Compact Stella
\end{tabular}

ZIncompatibility group.

${ }^{y}$ Although $S$-genotype of this group was originally assumed to be $S^{4} S^{5}$, recent study reassigned $S^{3} S^{5}$ to this group (Boskovic et al., 1997).

${ }^{x}$ Although $S$-genotype of this cultivar was originally assumed to be $S^{2} S^{5}$, recent study reassigned $S^{2} S^{x}$ to this cultivar (Boskovic et al., 1997).

kyo, Japan) for N-terminal amino acid sequencing (Tao et al., 1997).

CDNA LIBRARY CONSTRUCTION AND SCREENING. Total RNA was isolated from styles with stigmas of 'Satonishiki' at the balloon stage of development as described by McClure et al. (1990) with several minor modifications. $\operatorname{Poly}(\mathrm{A})^{+} \mathrm{RNA}$ was isolated from the total RNA using Oligotex-dT30 (Takara Shuzo Co., Shiga, Japan) and double-stranded cDNA was synthesized from the poly $(\mathrm{A})^{+} \mathrm{RNA}$ using oligo(dT) $)_{12-18}$ as a primer (cDNA Synthesis Kit; Pharmacia Biotech, Tokyo, Japan), cloned into $\lambda$ ZAPII vector (Stratagene, La Jolla, Calif.), and packaged in vitro using MaxPlax Packaging Extract Kit (Epicentre Technologies, Madison Wis.).

A partially degenerate primer (AS1: 5'-TAT TTT CAA TTT GTN CAG CAA TGG-3') was designed based on the N-terminal amino acid sequences of $S$-RNases of almond (Tao et al., 1997) and putative $S$-proteins of sweet cherry (Fig. 1), considering corresponding cDNA sequences of $S$-RNases of Japanese pear (Sassa and Hirano, 1997) and apple (Sassa et al., 1996). The primer was used in 3' rapid amplification of cDNA ends (3'RACE) with a commercial kit (3'RACE System for Rapid Amplification of cDNA Ends, Life Technologies, Tokyo, Japan). One microgram of total RNA from the styles with stigmas of 'Satonishiki' was used for first strand cDNA synthesis. PCR was performed using a program of 30 cycles at $94^{\circ} \mathrm{C}$ for $1 \mathrm{~min}, 60^{\circ} \mathrm{C}$ for $1 \mathrm{~min}$, and $72{ }^{\circ} \mathrm{C}$ for $1 \mathrm{~min} 30 \mathrm{~s}$ with an initial denaturing of $94^{\circ} \mathrm{C}$ for 3 min and a final extension of $72{ }^{\circ} \mathrm{C}$ for $5 \mathrm{~min}$. The PCR reaction mixture contained $10 \mathrm{~mm}$ Tris- $\mathrm{HCl}(\mathrm{pH} 8.3), 50 \mathrm{~mm} \mathrm{KCl}, 1.5 \mathrm{~mm}$ $\mathrm{MgCl}_{2}, 200 \mu \mathrm{M}$ each of dNTPs, $200 \mathrm{~nm}$ each of primers, the template cDNA equivalent to the amount synthesized from $0.1 \mu \mathrm{g}$ of the total RNA, and $1 \mathrm{U}$ of TaKaRa Ex Taq polymerase (Takara Shuzo Co., Shiga, Japan) in a $50 \mu \mathrm{L}$ reaction volume. The PCR products were subcloned into the TA cloning vector (TA Cloning kit; Invitrogen, San Diego, Calif.). Nucleotide sequences of the inserts of several clones were determined with an automatic DNA sequencer (model 373A; Applied Biosystems, Tokyo, Japan) and confirmed to include DNA sequence encoding N-terminal amino acid sequence of putative $S$-protein of sweet cherry. The insert was further PCR amplified with a primer set (Fig. 1), Pru-C2 (5'CTA TGG CCA AGT AAT TAT TCA AAC C-3') and Pru-C5 (5'TAC CAC TTC ATG TAA CAA CTG AG-3'), which were designed from the DNA sequence corresponding to the previously identified C2 and C5 conserved domains of solanaceous $S$ RNases (Tsai et al., 1992). PCR was performed using a program of 35 cycles at $94{ }^{\circ} \mathrm{C}$ for $30 \mathrm{~s}, 56^{\circ} \mathrm{C}$ for $30 \mathrm{~s}$, and $72^{\circ} \mathrm{C}$ for $30 \mathrm{~s}$ 
with an initial denaturing of $94^{\circ} \mathrm{C}$ for $3 \mathrm{~min}$ and a final extension of $72^{\circ} \mathrm{C}$ for $7 \mathrm{~min}$. The PCR reaction mixture was the same as described above except that the concentration of primers was increased to $400 \mathrm{~nm}$ and $10 \mathrm{ng}$ of plasmid DNA was used as a template. The amplified fragment of $\approx 400$ bp was labeled by random primer incorporation of DIG-dUTP (Boehringer Mannheim, Tokyo, Japan) and used as a probe to screen the primary cDNA library without amplification which consisted of $1 \times 10^{5}$ plaque forming units. Petri dishes ( $90 \mathrm{~mm}$ in diameter), each contained $\approx 1000$ plaques, were screened by plaque hybridization. After the low stringency washes $(2 \times 5 \mathrm{~min}$ at room temperature with $5 \times$ SSC and $0.1 \%$ SDS followed by $2 \times 15 \mathrm{~min}$ at $68^{\circ} \mathrm{C}$ with $1 \times \mathrm{SSC}$ and $0.1 \% \mathrm{SDS}$ ), colorimetric detection with nitroblue tetrazolium and 5-bromo-4-chloro-3-indolyl phosphate was conducted according to the manufacturer's protocol (Boehringer Mannheim). Selected clones were converted to pBluescript plasmids according to the manufacturer's protocol (Stratagene, La Jolla, Calif.) and DNA sequenced as described above.

3'RACE. Total RNA was isolated from styles with stigmas of 'Velvet' and 'Satonishiki' at the balloon stage of development as described above. One microgram of total RNA was used for first strand cDNA synthesis by $\mathrm{S}_{\mathrm{UPER}} \mathrm{S}_{\mathrm{CRIPT}}$ II RT (Life Technologies, Tokyo, Japan) with a primer Adp-dT (5'-CGA CGT TGT AAA ACG ACG GCC AGT TTT TTT TTT TTT TTT-3'), which comprises of M13-20 sequence primer (5'-CGA CGT TGT AAA ACG ACG GCC AGT-3') and oligo(dT) ${ }_{15}$. A primer, Pru-T2 (5'TST TST TGS TTT TGC TTT CTT C-3'), derived from the DNA sequence corresponding to the signal peptide sequence of $S$ RNase of sweet cherry (Fig. 1) was used in 3'RACE with M13-20 primer as an adapter primer. PCR was performed using a program of 30 cycles at $94^{\circ} \mathrm{C}$ for $30 \mathrm{~s}, 56^{\circ} \mathrm{C}$ for $30 \mathrm{~s}$, and $72^{\circ} \mathrm{C}$ for $1 \mathrm{~min}$ with an initial denaturing of $94^{\circ} \mathrm{C}$ for $3 \mathrm{~min}$ and a final extension of $72{ }^{\circ} \mathrm{C}$ for $7 \mathrm{~min}$. The PCR reaction mixture was described above. The PCR products were subcloned into the TA cloning vector (pGEM-T Easy Vector System; Promega, Madison, Wis.). Nucleotide sequences of the inserts of several clones were determined with an automatic DNA sequencer (model 373A; Applied Biosystems, Tokyo, Japan).

RNA BLOT ANALYSIS. Styles with stigmas, ovaries, petals, calyxes, peduncles, and anthers were dissected from the flower buds of 'Satonishiki' at the balloon stage of development. Young leaves of 'Satonishiki' were collected in spring. Total RNA was isolated from these samples as described above. Twenty micrograms of the total RNA was run in a formaldehyde (1\%) agarose gel, blotted onto a nylon membrane (Hybond-N, Amersham, Pharmacia, Biotech, Tokyo, Japan), probed with two different regions of the cDNAs, the C2-C5 and C5f-polyA fragments. The C2-C5 fragments of cDNAs were PCR labeled by DIG-dUTP with the Pru-C2 and Pru-C5 primers (Fig. 1). The C5f-polyA fragments of 3'RACE clones were also labeled by PCR with the Pru-C5f (5'-GTT GTT ACA TGA AGT GGT ATT TTG TTA TG$3^{\prime}$ ) and M13-20 primers (Fig. 1). After high stringency washes (2 $\times 5$ min at room temperature with $2 \times \mathrm{SSC}$ and $0.1 \% \mathrm{SDS}$ followed by $2 \times 15 \mathrm{~min}$ at $68^{\circ} \mathrm{C}$ with $0.1 \times \mathrm{SSC}$ and $0.1 \% \mathrm{SDS}$ ), immunological detection of the hybridization was carried out using the anti-DIG-alkaline phosphatase conjugate and the chemiluminescent substrate CSPD (Boehringer Mannheim, Tokyo, Japan). Chemiluminescence was documented on X-ray films.

GenOMIC DNA BLOT ANALYSIS. Total DNA was isolated from young leaves by the CTAB method (Doyle and Doyle, 1987), using all the cultivars listed in Table 1. After purifying the isolated DNA by PEG precipitation (Mak and Ho, 1993), $5 \mu \mathrm{g}$ of DNA was digested either with EcoRI or HindIII and run on $0.8 \%$ agarose gel, transferred to a nylon membrane (Hybond-N, Amersham), and probed with the C2-C5 and C5f-polyA fragments of the cDNAs. After high stringency washes $(2 \times 5 \mathrm{~min}$ at room temperature with $2 \times \mathrm{SSC}$ and $0.1 \%$ SDS followed by $2 \times 15 \mathrm{~min}$ at $68^{\circ} \mathrm{C}$ with $0.1 \times$ SSC and $0.1 \%$ SDS), immunological detection of the hybridization was carried out as described above for RNA blot analysis.

PCr amplification of S-alleles. As described above for the genomic DNA blot analysis, total DNA was isolated and purified from all the cultivars listed in Table 1 and used as template DNA for PCR. PCR was performed using a program of 35 cycles at 94 ${ }^{\circ} \mathrm{C}$ for $1 \mathrm{~min}, 56^{\circ} \mathrm{C}$ for $1 \mathrm{~min}$, and $72^{\circ} \mathrm{C}$ for $1 \mathrm{~min} 30 \mathrm{~s}$ with an initial denaturing of $94^{\circ} \mathrm{C}$ for $3 \mathrm{~min}$ and a final extension of $72{ }^{\circ} \mathrm{C}$ for $7 \mathrm{~min}$. The PCR reaction mixture contained $10 \mathrm{~mm}$ Tris- $\mathrm{HCl}$ ( $\mathrm{pH}$ 8.3), $50 \mathrm{~mm} \mathrm{KCl}, 1.5 \mathrm{~mm} \mathrm{MgCl}, 200 \mu \mathrm{M}$ each of dNTPs, 400 nM each of primers, $50 \mathrm{ng}$ of template DNA, and $1 \mathrm{U}$ of TaKaRa Ex Taq polymerase (Takara Shuzo Co., Shiga, Japan) in a $50 \mu \mathrm{L}$ reaction volume. Two different primer sets, Pru-T2 and Pru-C4R (5'-GGA TGT GGT ACG ATT GAA GCG-3'), and Pru-C2 and Pru-C4R (Fig. 1), were used. After PCR, PCR mixture was run on $1.5 \%$ agarose gel and DNA bands were visualized by ethidium bromide staining. Then the DNA in the gel was blotted to a nylon membrane (Hybond-N, Amersham, Pharmacia Biotech, Tokyo, Japan) and probed with the C2-C5 fragments of $S^{2}$-cDNA to confirm that the bands observed are truly from $S$-alleles. The C2C5 fragments of $S^{2}$-cDNA was labeled by DIG-dUTP as described above. After high stringency washes $(2 \times 5 \mathrm{~min}$ at room temperature with $2 \times \mathrm{SSC}$ and $0.1 \% \mathrm{SDS}$ followed by $2 \times 15 \mathrm{~min}$ at $68^{\circ} \mathrm{C}$ with $0.1 \times \mathrm{SSC}$ and $0.1 \%$ SDS), immunological detection of the hybridization was carried out using the anti-DIG-alkaline phosphatase conjugate and the colorimetric detection with nitroblue tetrazolium and 5-bromo-4-chloro-3-indolyl phosphate was conducted according to the manufacturer's protocol (Boehringer Mannheim).

\section{Results}

Protein assay. A group of proteins with $M r$ and $\mathrm{pI}$ similar to those of $S$-RNase of almond (Tao et al., 1997) were found in the 2D-PAGE profiles after silver staining (Fig. 2A). These proteins were present at highest concentration in upper segment (Fig. 3A) of the mature style (Fig. 3B) and contained sugar chains reacting with concanavalin A (Fig. 2B, left). In this $S$-like glycoprotein group, there were at least four different glycoproteins (the spots I, II, III, and IV) with different $M r$ and pI values (Fig. 2C). Two or three of them were seen in each cultivar, and cultivars with the same $S$-genotype yielded the same spots. 'Compact Stella' showed the same spot pattern as $S^{3} S^{4}$ cultivars, which is consistent with the observation that both $S^{3}$ and $S^{4 m}$-alleles function in the style of 'Compact Stella'. Among the $S$-like glycoprotein group, spots associated with $S^{2}$ and $S^{6}$-alleles could be found. The most basic $S$-like protein spot IV was only observed in the cultivars with $S^{2}$ allele and the second basic spot III in the cultivars with $S^{6}$-allele (Fig. 2A and C). Thus the former seemed to be $S^{2}$ allelic product and the latter to be $S^{6}$ product. For 'Satonishiki' and 'Velvet', the putative $S^{2}$ and $S^{6}$-allelic products along with two other $S$-like glycoprotein spots (the spots A and B of 'Velvet' and the spots A' and B' of 'Satonishiki') reacted with the anti-S4-serum, and were shown to be immunologically similar to $S$-RNase of Japanese pear (Fig. 2B, right). Other proteins that showed polymorphism among cultivars with the same $S$-genotype (data not shown) were also reactive to the antiserum (Fig. $2 \mathrm{~B}$, right, non- $S$ ). The $\mathrm{N}$-terminal 
gtgatggatcttacgactattttcaatttgtgcaacaatggecacegaccaactgcagagttcgcatcaagcgaccttgctccaacccccggcca GTGATGGATCTTATGTCTATTTTCAATTTGTGCAACAATGGCCACCGACCACCTGCAGAGTTCAGAAGAA------ATGCTCTAAACCCCGGCCa ---- GATCTTATGTCTATTTTCAATTTGTGCAACAATGGCCACCGACCAACTGCAGAGTTCGCATCAAGCGACCTTGCTCCAGTCCCCGGCCa

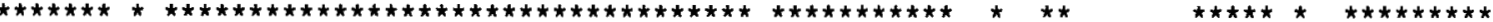

AS1

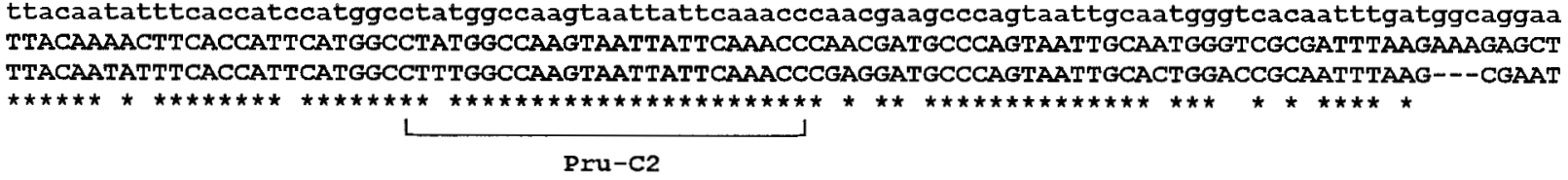

agtgtcacctcagttgcgagccaaactgaagagatcttggcccgacgtggaaagtggcaatgatacaagattttgggaaggcgaatggaacaaac ATTGTCCCCTCGAATGCAATCCAAACTGAAGATATCTTGGCCGAACGTTGTAAGTAGCAACGATACAAAATTTTGGGAAAGTGAATGGAACAAAC ATTGTCCCCTCAACTGCGATCCAAACTGCAGACATCTTGGCCGGACGTGGAAAGTGGCAATGATACAAAGTTTTGGGAAAGCGAATGGAACAAAC

Atggtagatgttccgaacagactcttaaccaaatgcaatacttcgagcgatcccaaaacatgtggaggtcgtacaatattacagagatccttaga aTGGTACTTGTTCCGAACAGACACTTAACCAAGTGCAATACTTCGAGATATCCCACGAAATGTGGAACTCGTTCAATATTACAGATATCCTTAAA aTGGTACATGTTCCAAAGAGACACTTAACCAAATGCAGTACTTCGAGCGATCCTACGCAATGTGGATGTCGTACAATATTACAGAGATCCTTAAA

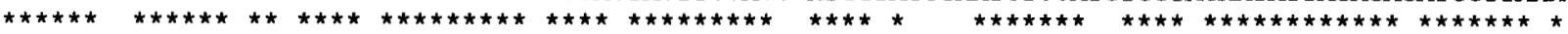

Pru-C4R

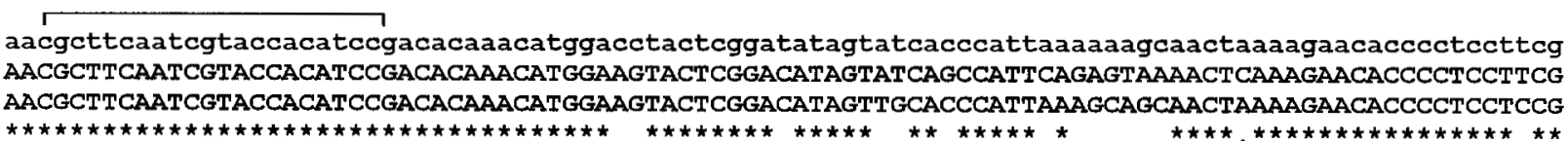

Pru-C5

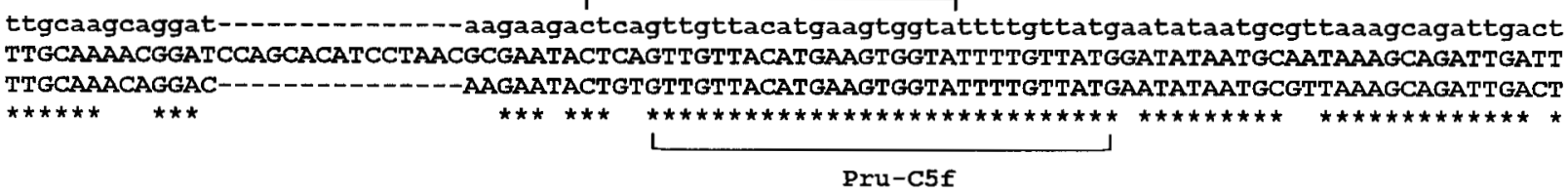

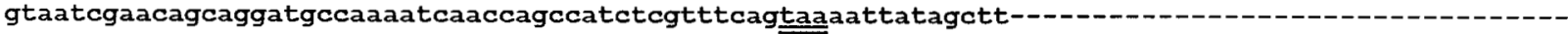
GTAATCGAACAGCAGGATGCAAAAATCAAGTTAACATCTTGTTTCCATAAAATGATAGCTTTTCGAAGTCATCACAAAGTACGATTGTTTTTCAC GTAATCGAACATCCGGATGCCAAAATCAACCAGCCATCTCGTTTCAATAAATTATAGCTAG-

Fig. 1. Nucleotide sequences of the $S^{2}, S^{3}$, and $S^{6}$-cDNAs of sweet cherry. The alignment was generated by CLUSTAL W version 1.6 (Thompson et al., 1994). Gaps are marked by dashes. Conserved nucleotides are indicated by asterisks. Nucleotide sequences shown in small case are only from the 3'RACE clones and those shown in large case are from the clones screened from the cDNA library. The initiation and stop codons are double underlined. Sequences used to design oligonucleotide primers are indicated with the name of primers (Pru-T2, AS1, Pru-C2, Pru-C4R, Pru-C5, and Pru-C5f). 

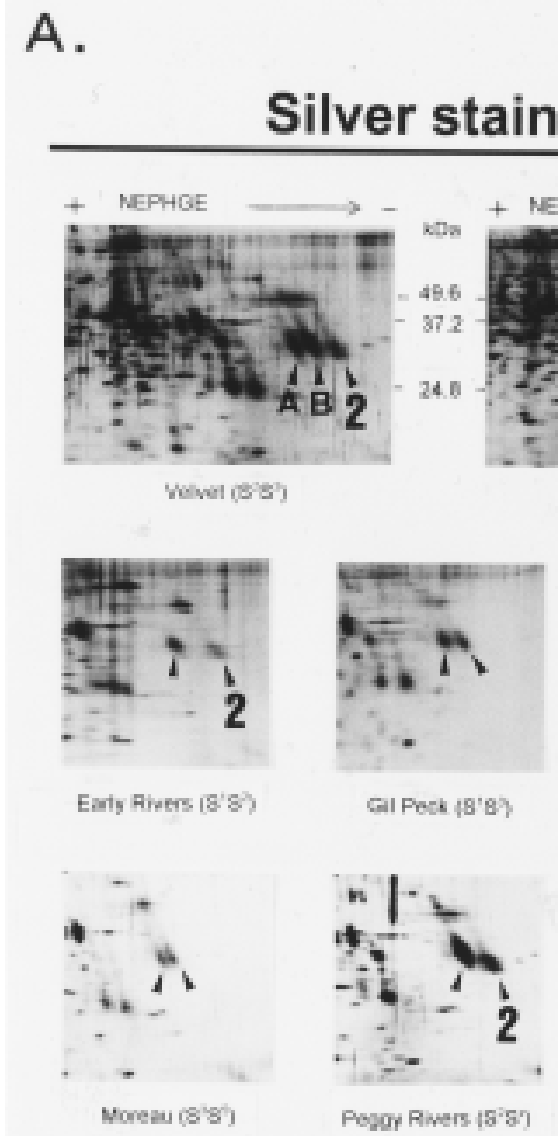

Sacosishai (8) (8)

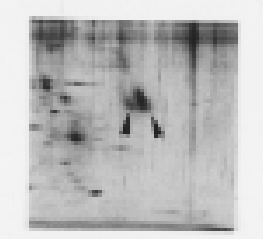

Bing $\left.68^{\prime} 8^{\prime}\right)$

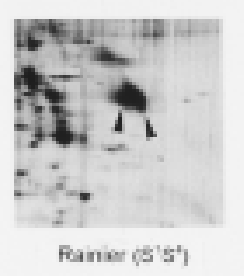

B.

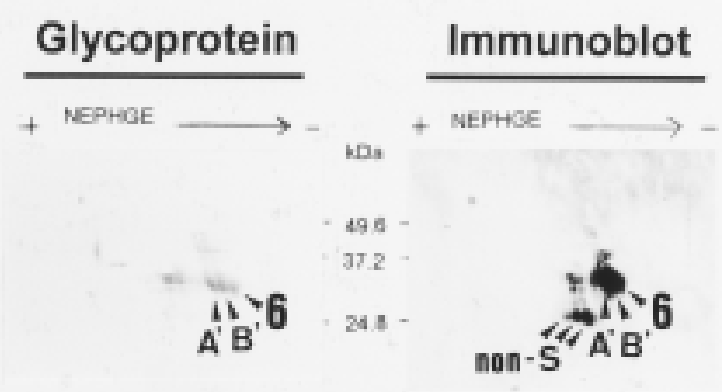

Satonishiki $\left(\mathbf{S}^{3} \mathbf{S}^{6}\right)$
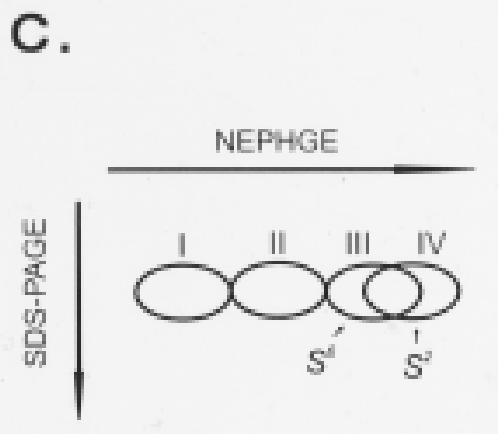

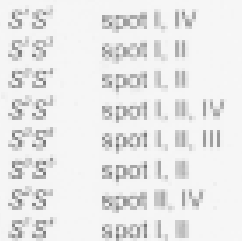

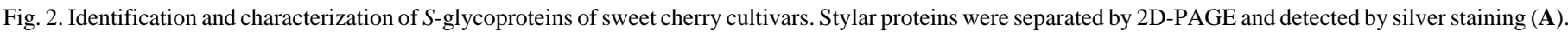

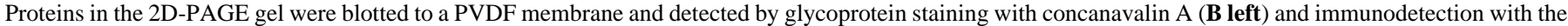

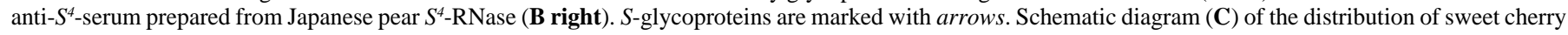
$S$-glycoproteins in 2D-PAGE profiles.

amino acid sequence of the putative $S^{2}$ and $S^{6}$-proteins were highly homologous to each other and to those of the $S$-RNase of almond and other rosaceous species (Fig. 4). The N-terminal amino acid sequences of the spots $\mathrm{A}, \mathrm{A}^{\prime}, \mathrm{B}$, and $\mathrm{B}^{\prime}$ also share the similarity with those of putative $S^{2}$ and $S^{6}$-proteins and to that of the $S$-RNase of almond and other rosaceous species. Either spots $A$ and $A^{\prime}$ or spots B and B' might be the $S^{3}$-protein because spots A and $\mathrm{A}^{\prime}$ showed identical $\mathrm{N}$-terminal sequences as did spots $\mathrm{B}$ and $\mathrm{B}^{\prime}$. The sequence of spots $\mathrm{A}$ and $\mathrm{A}^{\prime}$ differs from the sequence of spots $\mathrm{B}$ and $\mathrm{B}^{\prime}$ only in that the former contain two additional amino acids, Asp and Gly at the N-terminus.

cDNA CLONING. For several 3'RACE clones obtained, DNA sequences following the AS1 primer sequence were confirmed to encode amino acid sequences of the putative products of $S^{3}$ (PPTTxRVQKK) or $S^{6}$ (PPTNxRVRIK) (Fig. 4). These clones were further PCR amplified by the Pru-C2 and Pru-C5 primers and used as probes to screen the cDNA library. About 90,000 plaques were screened by these probes and seven positive plaques with an insert length longer than $700 \mathrm{bp}$ were obtained. Under the low stringency wash condition we used, these plaques hybridized to both probes. When these were converted to pBluescript and PCR amplified by the Pru-C2 and Pru-C5 primers, all seven clones gave PCR products of $\approx 400 \mathrm{bp}$, expected size from the 3'RACE clones used for probes. $\mathrm{MboI}$ digests of the PCR products showed that these were identical to 3'RACE clones; six of them gave the same restriction fragment pattern as that of the 3'RACE clone encoding the putative $S^{3}$-allelic product and one gave that encoding the putative $S^{6}$-allelic product (data not shown). DNA sequencing of two clones for the former and one for the latter confirmed that they contained the sequences encoding the $\mathrm{N}$ terminal amino acid sequences of the putative $S^{3}$-and $S^{6}$-allelic products, respectively. Although the 3 ' untranslated region of the putative $S^{6}$-cDNA clone was truncated, both the cDNA clones contained the entire coding sequences (Figs. 1 and 5). The putative $S^{3}$ and $S^{6}$-cDNAs include open reading frames of 687 and 669 nucleotides (Fig. 1), which encode 229 and 223 amino acid residues (Fig. 5), respectively. Deduced amino acid sequences from the cDNAs contained putative signal peptide comprising of $\approx 25$ amino acid residues at the N-terminal (Figs. 4 and 5). The Pru$\mathrm{T} 2$ primer was designed from the DNA sequences corresponding to the signal peptide sequence of the putative $S^{3}$ and $S^{6}$ of 'Satonishiki' (Fig. 1) and used for 3'RACE to obtain information on the 3' untranslated regions and to compare the $S$-alleles of different cultivars. The Pru-T2 primer was successfully used to obtain 3'RACE clones encoding putative $S^{2}$ and $S^{3}$ of 'Velvet' and $S^{3}$ and $S^{6}$ of 'Satonishiki'. For 'Velvet', 24 independent 3'RACE clones of $\approx 750$ bp that could be PCR amplified with the Pru-C2 and Pru-C5 primers were obtained. MboI digest of the amplified products suggested that one of them was identical to the putative $S^{3}$-cDNA from the cDNA library of 'Satonishiki'. DNA sequencing confirmed that they contained exactly the same sequence as the putative $S^{3}$-cDNA from the cDNA library of 'Satonishiki' (Figs. 1 and 5). The remaining 23 clones yielded the same restriction fragments but the fragment pattern was different from 


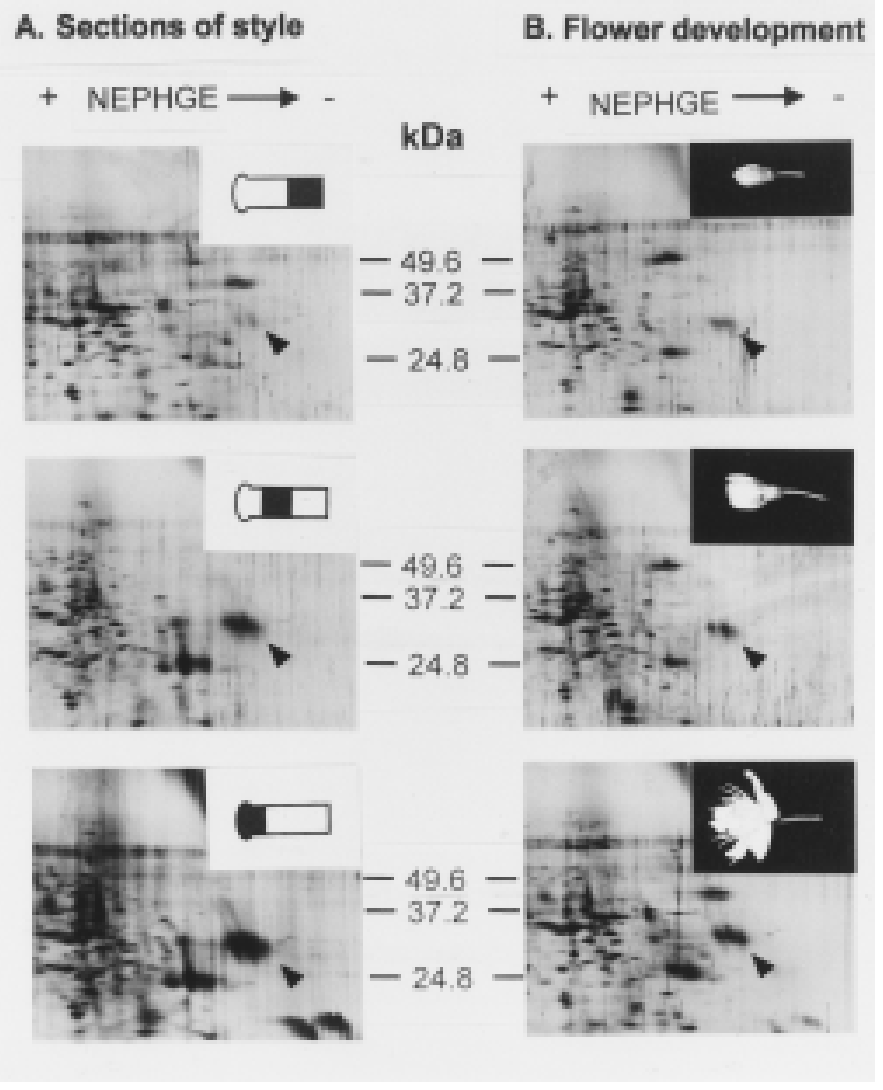

Fig. 3. Spatial (A) and developmental (B) regulations of $S$-glycoprotein expression in 'Satonishiki' sweet cherry $\left(S^{3} S^{6}\right)$. Crude extracts prepared from the lower, middle, and upper portions of the styles (A) or styles with stigmas at different stages (white bud, balloon, and full bloom) of flower bud development $(\mathbf{B})$ were subjected to 2D-PAGE and proteins were detected by silver staining. $S$ glycoproteins are marked with arrowheads.

that of the putative $S^{3}$-cDNA, suggesting that they were $S^{2}$-cDNA. DNA sequencing of these clones confirmed that they contained the sequence encoding the $\mathrm{N}$-terminal amino acid sequence of the putative $S^{2}$-protein (Figs. 1, 4, and 5). For 'Satonishiki', 10 independent 3'RACE clones were obtained. When PCR products obtained with the Pru-C2 and Pru-C5 primers were digested by $M b o I, 9$ yielded the same restriction fragment pattern as that of the putative $S^{3}$-cDNA and the remaining one showed the same pattern as putative $S^{6}$-cDNA from the cDNA library. DNA sequencing was performed for the two types of the clones and confirmed that they were identical to the putative $S^{3}$-and $S^{6}$-cDNA clones from the library (Fig. 1).

RNA BLOT ANALYsis. A hybridization signal at $800 \mathrm{bp}$ was detected only with the total RNA isolated from styles with stigmas. The total RNAs from petals, ovaries, calyxes, anthers, peduncles, and young leaves gave no hybridization signal (Fig. 6). There was no difference in the size of the band obtained from the four different probes used, the $\mathrm{C} 2-\mathrm{C} 5$ and the C5f-polyA fragments from the putative $S^{3}$ and $S^{6}$-cDNAs (data not shown).

GeNomic DNA BLOT ANALYSIS. The C2-C5 fragments of putative cDNA clones (Fig. 1) of different $S$-alleles seemed to be similar enough to each other to cross-hybridize with any of the $S$ alleles even under high stringency wash conditions. One or two bands were observed with all cultivars and with all probes (Fig. 7). Cultivars with the same $S$-genotypes gave the same hybridization signal and each band observed on the blot could be assigned to an $S$-allele. With HindIII digestion, $S^{l}$ and $S^{3}$-alleles gave $8.8 \mathrm{~kb}$ fragments and $S^{2}, S^{4}$, and $S^{6}$-alleles gave $5.7 \mathrm{~kb}$ fragments (Fig. 7). The $S^{5}$-allele gave a unique fragment of $3.1 \mathrm{~kb}$. When the C5fpolyA fragment of the putative $S^{3}$-cDNA was used as a probe, it specifically hybridized with the $S^{3}$-allele. A single band at $8.8 \mathrm{~kb}$ could be detected only with cultivars with $S^{3}$-allele (Fig. 7), although the C5f-polyA fragments of $S^{2}$ and $S^{6}$-alleles crosshybridized to all $S$-alleles. With $E c o$ RI digestion, $S^{2}, S^{3}, S^{5}$, and $S^{6}$ alleles gave unique fragments of $4.4 \mathrm{~kb}, 13.1 \mathrm{~kb}, 7.9 \mathrm{~kb}$, and 11.0 kb, respectively (Fig. 7). $S^{l}$ and $S^{4}$-alleles gave the same fragment of $1.5 \mathrm{~kb}$. When the results obtained with HindIII and EcoRI digestions were combined, $S^{l}$ to $S^{6}$-alleles could be distinguished from each other. Based on the DNA blot analysis, $S$-genotype of 'Peggy Rivers' was suggested to be $S^{2} S^{4}$ (Fig. 7). The $S^{4 m}$-allele of 'Compact Stella' gave exactly the same fragment as $S^{4}$-allele of other cultivars, which is consistent with the observation that the $S^{4}$-protein was present in the style of 'Compact Stella'.

PCR AMPlification of S-alleles. As shown in Fig. 8, when combined with the results obtained from the two primer sets, $S^{l}$ to $S^{6}$-alleles could be distinguished from each other. With the Pru-T2 and Pru-C4R primers, $S^{6}, S^{1}$, and $S^{4}$-alleles gave the unique bands of 980,1220 , and $1500 \mathrm{bp}$, respectively, although $S^{3}$ and $S^{5}$-alleles gave the same bands of $1100 \mathrm{bp}$. With this primer set, the $S^{2}$-band at $2500 \mathrm{bp}$ was faint. When the Pru-C2 and Pru-C4R primers were used, $S^{3}$ and $S^{5}$-alleles gave different bands of 750 and $680 \mathrm{bp}$, respectively, and could be distinguished from each other, although $S^{1}$ and $S^{3}$-alleles gave the same bands. With this primer set, the $S^{2}$-allele could be amplified well and gave the unique band at $2100 \mathrm{bp} . S^{4}$ and $S^{6}$-alleles gave unique bands at 1000 and $500 \mathrm{bp}$, respectively. All the bands amplified with these two primer sets hybridized with the C2-C5 fragment of the $S^{2}$-cDNA, which confirmed that they were derived from $S$-alleles. As with the DNA

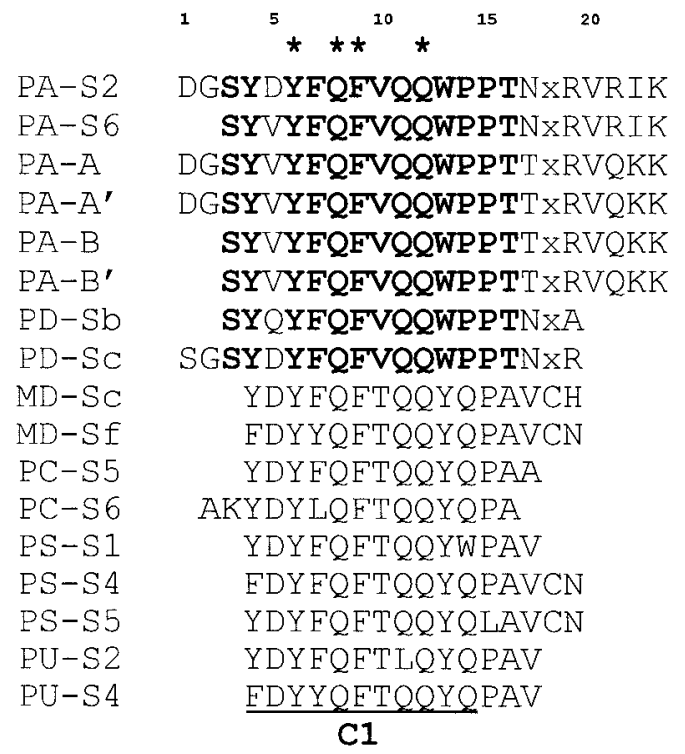

Fig. 4. Alignment of N-terminal amino acid sequences of $S$-proteins of sweet cherry and other rosaceous $S$-RNases. Amino acid sequences corresponding to the $\mathrm{C} 1$, previously reported conserved domain of solanaceous $S$-RNases (Tsai et al., 1992), is indicated at the bottom. Amino acid residues conserved in all Prunus $S$-RNases are indicated by bold face and those conserved in all rosaceous $S$-RNases are marked with asterisks. Plant species from which each sequence is derived are denoted by the initials of their scientific names, i.e., PA refers to Prunus avium. Sequence data for the $S$-RNases included are as follows: $S^{b}$ and $S^{c}$ of Prunus dulcis (almond) (Tao et al., 1997); $S^{c}$ and $S^{f}$ of Malus $\times$ domestica (apple) (Sassa et al., 1996); $S^{5}$ and $S^{6}$ of Pyrus communis (European pear) (Tomimoto et al., 1996); $S^{l}, S^{4}$, and $S^{5}$ of Pyrus serotina (synonim of Pyrus pyrifolia) (Japanese pear) (Sassa et al., 1993, 1996); $S^{2}$ and $S^{4}$ of Pyrus ussuriensis Maxim (Chinese pear) (Tomimoto et al., 1996). 


\section{$\mathrm{PA}-\mathrm{S} 2$ \\ $\mathrm{PA}-\mathrm{S} 3$ \\ PA-S6 \\ MD-SC \\ PS-S5 \\ $\mathrm{AH}-\mathrm{S} 4$ \\ $\mathrm{NA}-\mathrm{S} 2$ \\ $\mathrm{PI}-\mathrm{S} 1$ \\ ST-S2 \\ $\mathrm{PA}-\mathrm{S} 2$ \\ $\mathrm{PA}-\mathrm{S} 3$ \\ $\mathrm{PA}-\mathrm{S} 6$ \\ MD-SC \\ PS-S5 \\ $\mathrm{AH}-\mathrm{S} 4$ \\ $\mathrm{NA}-\mathrm{S} 2$ \\ PI-S1 \\ $\mathrm{ST}-\mathrm{S} 2$}

PA-S2

$\mathrm{PA}-\mathrm{S} 3$

$\mathrm{PA}-\mathrm{S} 6$

$M D-S C$

PS-S 5

$\mathrm{AH}-\mathrm{S} 4$

$\mathrm{NA}-\mathrm{S} 2$

PI-S 1

ST-S2

PA-S2

$\mathrm{PA}-\mathrm{S} 3$

$\mathrm{PA}-\mathrm{S} 6$

MD-SC

PS-S5

$\mathrm{AH}-\mathrm{S} 4$

$\mathrm{NA}-\mathrm{S} 2$

PI-SI

$\mathrm{ST}-\mathrm{S} 2$

$\mathrm{PA}-\mathrm{S} 2$

$\mathrm{PA}-\mathrm{S} 3$

$\mathrm{PA}-\mathrm{S} 6$

MD-SC

PS-S 5

$\mathrm{AH}-\mathrm{S} 4$

$\mathrm{NA}-\mathrm{S} 2$

PI-S1

ST-S2

CE IMST TEGSYDYFQFVQQWPPTNCRVRI KRPCSNPRP MAMLKSSL---SFLVLGFAFFLCF I ISAGDGSYVYFQFVQQWP PTTCRVQKK--CSKPRP MAMLKSSP---AFLVLAFAFFLCF IMSNG--SYVYFQFVQQWP PTNCRVRI KRPCSS PRP --MGITGM- - IYMVTMVFS L IVLILSS PTVGYDYFQFTQQYQPAVCHENPT-PCRDP-P --MGITGM-- VYVVTMVFLLIVLILSSSTVGYDYFQFTQQYQLAVCNSNRT-PCKDP-P MAMI KKNRKVN P LS LLVVCVVP LNCCSTI IAKCDYLKLVLQWPKS FCLINSR-KCQRNPI --MSKSQ------ ITSVFFI LLCALS P IYGAFEYMQLVLTWP ITFCRI KH---CERT---MVKSR------IISVFFIFLFS FSPVYGNFEYLQLVLTWPASFCFRP KN-ICKRP--- MAKSQ------LVSALFVFFFSLSPIYGDFDYMQLVLTWPRSFCYPRGF- -CNRIP*
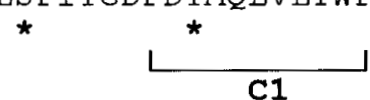

LQYFTI HGLWPSNYSN PT KPSNCNGSQFDGRKVSPQLRAKLKRSWP----DVESGND-TR LQNFT I HGLWP SNYSNPTMPSNCNGSREKKELLSPRMQSKLKI SWP---NVVS SND-TK LQYFT I HGLWP SNYSN P RMP SNCTGPQEKR-I LSPQLRSKLQT SWP----DVESGND-TK DKLFTVHGLWP SNSSGN-DP I YCKNTTMNS-TKIANLTARLEI IWP----NVLDRTDHIT DKLFTVHGLWP S SMAGP-DP SNCPIRNIR--KREKLLEPQLAI IWP----NVFDRTKNKL PSNET I HGLWP DNYTRQ-APQSCTTNNFQR-FTDTDIEQRMEESWPDLK-QQSIAGLSYN PTNFT I HGLWPDNHTTM--LNYCDRSKPYNMFTDGKKKNDLDERWPDLTKTKFDSLDKQA AKNFT I HGLWPEITGFR--LEFCTGSPKYET FKDNNIVDYLERHWVQMKFDENYAKYHQP PNNFTI HGLWP DKKPMRGQLQFCT-SDDYI KFTPGSVLDALDHHWIQLKFEREIGIRDQP
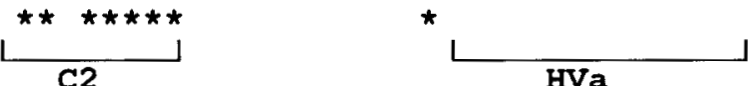

HVa

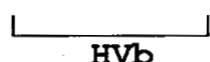

HVb

FWEGEWNKHGRCSEOTL-NOMOYFERSONMWRS--YNITEI LRNAS IVPHPTOTWTYSDI FWES EWN KHGTCSEQTL-NQVQYFEI SHEMWNS-- FNIT DI LKNAS IVPHPTQTWKYSDI FWESEWNKHGTCSKETL-NQMQY FERSYAMWMS--YNITEI LKNASIVPHPTQTWKYSDI FWNKOWNKHGSCGHPAIONDMHYLQTVI KMYITQKONVSEI LSKAKIEPV-GKFRTOKEI FWDKEWMKHGTCGYPT I DNENHYFETVI KMYI S KKONVSRI LS KAKIEPD-GKKRALLDI FWQDQWRKHGSCCFP PH-ESEI YFLKALELKDR--LDVLTILENNN FNPGTPQPFSVLRV FWKDEYVKHGTCCSDKF-DREQYFDLAMTLRDK--FDLSS-LRNHGI SRG--FSYTVQNL LWSYEYRKHGMCCSKIY-NQKAYFLLATRLKEK--FDLLTTLRTHGITPG--TKHTFGDI LWKDQYKKHGTCCLPRY-NQLQYFLLAMRLKEK--FDLLTTLRTHGITPG--TKHTFKKI

*

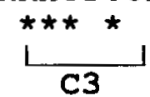
*

VSPI KKAT-KRTPLLRCKOD-----KKTOLLHEVVFCYEYNALKOIDCNRTAG------VSAIQSKT-QRTPLLRCKTDPAHPNANTQLLHEVVECYGYNAIKQIDCNRTAG------VAPI KAAT-KRTPLIRCKQD-----KNTVLLHEVVFCYEYNALKQIDCNRT SG----- EKAIRKGTNNKEPKLKCQKN-----SQRTELVEVTICSDRNLNQF IDCPRP I LNGSRYYENAIRNGADNKKPKLKCOKK-----GTTTELVEITLCSDKSGEHFIDCPHPFEPIS PHYFNT ISRAI -GKTPILKCAQS----_--YLKEVVICVDNNGASVVHCPRSRPRPRPRRD NNTIKAIT-GGFPNLTCSR------ LRELKEI GICFDETVKNVIDCPNPKT-----QKAIKTVTNQVDPDLKCVEH----IKGVQELNEI GICFNPAADN FYPCHHSYT----.-QDAI KTVT-QEVPDLKCVEN----IQGVLELYEIGICFTPEADSLFPCRQSKS------* *

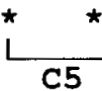

$$
\begin{aligned}
& \text {-CQNQP--AISEQ- } \\
& \text {-CKNQV--NILFP- } \\
& \text {-CQNQP--AISFQ- } \\
& \text {-CPTN--NILY- } \\
& \text { - CPTN---NIKY- } \\
& \text { PCPFS--DVKFP- } \\
& \text {-CKPTNKGVMFP- } \\
& \text {-CDETDSKMILFR- } \\
& \text {-CHPTENPLILFRL } \\
& \text { * }
\end{aligned}
$$

Fig. 5. Amino acid sequence alignment of sweet cherry $S$-RNases and other $S$-RNases. The alignment was generated by CLUSTAL W version 1.6 (Thompson et al., 1994). Gaps are marked by dashes. Signal peptide sequences of rosaceous RNases are indicated by italics. The five conserved regions and the two hypervariable regions reported in the solanaceous $S$-RNases are shown under the sequences (Ioerger et al., 1990; Kheyr-Pour et al., 1990). Conserved residues in all $S$-RNases are indicated by asterisks. Potential $N$-glycosylation sites are indicated by bold face. Plant species from which each sequence is derived are denoted by the initials of their scientific names, i.e., PA means Prunus avium. Sequence data for the $S$-RNases included are as follows: $S^{c}$ of Malus $\times$ domestica (apple) (Sassa et al., 1996); $S^{5}$ of Pyrus serotina (synonym of Pyrus pyrifolia)(Japanese pear) (Sassa et al., 1997); $S^{4}$ of Antirrhinum hispanicum (Xue et al., 1996); $S^{2}$ of Nicotiana alata (Anderson et al., 1986); $S^{I}$ of Petunia inflata (Coleman and Kao, 1992); $S^{2}$ of Solanum tuberosum (Kaufmann et al., 1991). 
Fig. 6. RNA blot analysis of total RNA from leaf (Lf), calyx (Cx), petal $(\mathrm{Pt})$, peduncle $(\mathrm{Pd})$, anther (At), ovary (Ov), and style with stigma (St) from flower buds of 'Satonishiki' at the balloon stage of development. (A) The blot was hybridized to the $\mathrm{C} 2-\mathrm{C} 5$ fragment of $S^{3}$-cDNA. (B) Ethidium bromide-stained gel before blotting.

blot analysis (Fig. 7), the $S$ genotype of 'Peggy Rivers' was suggested to be $S^{2} S^{4}$ and the $S^{4 m}$-allele of 'Compact Stella' gave the same band as $S^{4}$-allele of other cultivars.

\section{Discussion}

In this study, we first used 2D-PAGE to identify basic stylar glycoproteins associated with $S$-alleles of sweet cherry cultivars. As expected, putative $S$-glycoproteins of sweet cherry were found (Figs. 2 and 3) in the same area of the 2D-PAGE gels as the area where $S$-RNases of almond were located (Tao et al., 1997). These putative $S$-glycoproteins were concentrated in upper segments of styles (Fig. 3) where the arrest of incompatible pollen tube growth occurs (Pimienta et al., 1983, Raff et al., 1982). Furthermore, concentrations of the putative $S$-glycoproteins became higher as styles matured (Fig. 3 ), which correlates with the ability of the style to reject self-incompatible pollen tube growth. It has been reported that incompatible pollen tube growth cannot be fully inhibited by young immature styles of Japanese pear (Hiratsuka and Hirata, 1985).

Although there were six $S$-allelic products tested, only four different putative $S$-glycoprotein spots were found on the 2D-PAGE, probably because some of the $S$-allelic products overlapped on the gel. In this putative $S$ glycoprotein group, spots corresponding to $S^{2}$ and $S^{6}$-alleles were found. Not only the $M r$ and pI values but also immunological characteristics (Fig. 2B, right) and N-terminal amino acid sequences (Fig. 4) of these proteins were similar to those of almond $S$-RNases (Tao et al., 1997). There were several other protein spots that were reactive to the anti- $S^{4}$-serum (Fig. 2B, right, non-S), which had smaller $\mathrm{Mr}$ and $\mathrm{pI}$ values than putative $S$-RNases. We ruled out the possibility of these proteins being $S$-proteins for the following two reasons. First, polymorphism was observed with these proteins among the cultivars with the same $S$ genotypes. Second, the N-terminus of these proteins seemed to be blocked although those of $S$-RNases reported so far for the Rosaceae were not blocked (Ishimizu et al., 1996; Sassa et al., 1993; Tomimoto et al., 1996). Since the $\mathrm{N}$-terminal of non- $S$-RNase of Japanese pear is blocked (Norioka et al., 1996) and non-S-RNase activity bands of almond reacted with the antiserum (Tao et al., 1997), they might be non- $S$-RNases of sweet cherry.
After identifying the putative $S$-glycoproteins by 2D-PAGE, cDNAs encoding them were cloned based on their N-terminal amino acid sequences. Several findings indicated that the cDNA clones encode $S$-RNases. The DNA sequences corresponded to the N-terminal sequences of the putative $S$-proteins identified by 2D-PAGE. Also, the deduced amino acid sequences from the cDNAs contained two active sites, the $\mathrm{C} 2$ and $\mathrm{C} 3$ domains, of RNase T2 (Kawata et al., 1988) and Rh (Horiuchi et al., 1988), and two (C1 and $\mathrm{C} 5)$ of the other three conserved domains among the solanaceous $S$-RNases (Tsai et al., 1992). Although the C4 domain reported by Tsai et al. (1992) was absent, sequence matching with the C4 domain of solanaceous $S$-RNases has not been reported for the other rosaceous and scrophulariaceous $S$-RNases either (Norioka et al., 1996; Sassa et al., 1996; Xue et al., 1996). In addition to the similarity in the conserved domains, eight cysteine residues conserved among other $S$-RNases were conserved in the sweet cherry sequences and potential $N$-glycosilation sites that were conserved in Malus and Pyrus $S$-RNases (Sassa et al., 1996) were present in sweet cherry (Fig. 5). Further evidence was obtained from RNA blot analysis using the portions of cDNAs as probes. As shown in Fig. 6, RNA blot analysis showed that the genes were specifically transcribed in styles, which is consistent with the expression pattern of other rosaceous $S$ RNases (Sassa et al., 1996). Last evidence was obtained from DNA blot analysis using the cDNAs as probes. As shown in Fig. 7 , the C5f-polyA fragment of the putative $S^{3}$-cDNA hybridized only with genomic DNA from cultivars with the $S^{3}$-allele. Al-

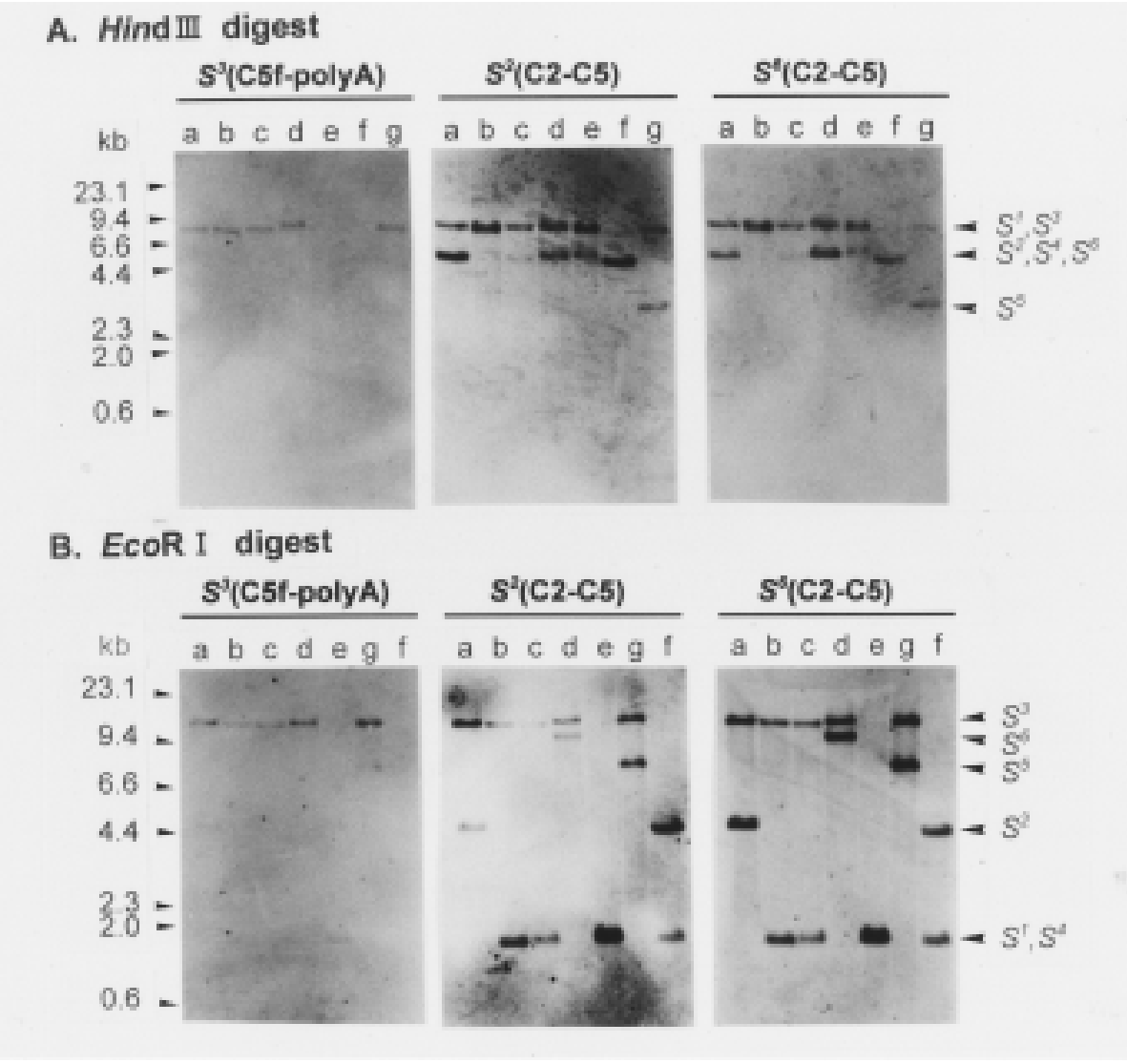




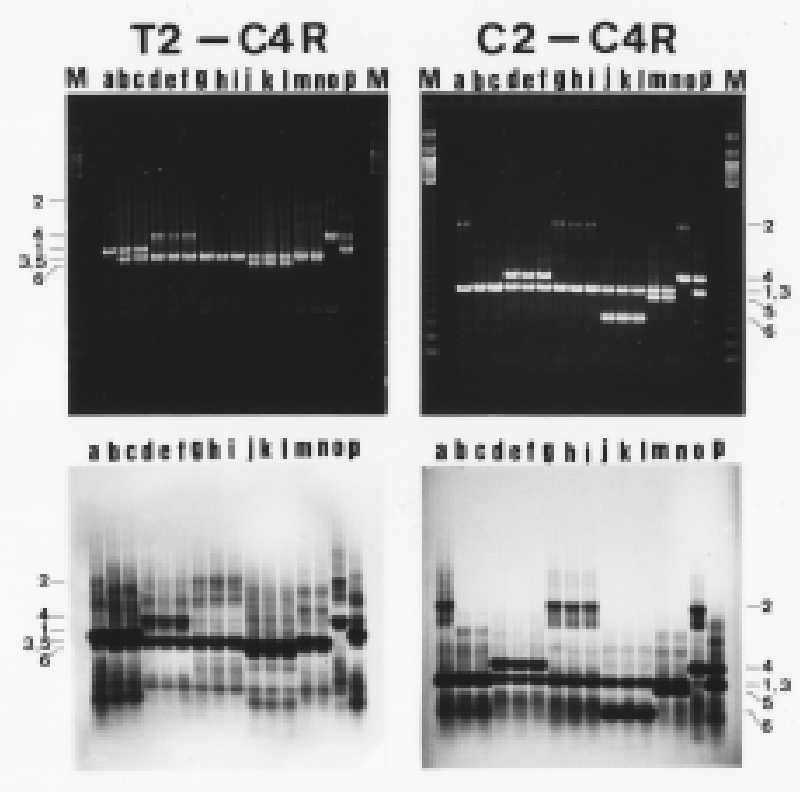

Fig. 8. PCR analysis for $S$-allele typing. Genomic DNA was PCR amplified with two primer sets (Pru-T2 + Pru-C4R and Pru-C2 + Pru-C4R), separated on an agarose gel and detected with ethidium bromide staining (upper photograph). The gel was then blotted onto a nylon membrane, and probed and detected with the C2-C5 fragment of $S^{2}$-cDNA (lower photograph). M: 123 bp DNA ladder. (a) Early Rivers $\left(S^{l} S^{2}\right)$, (b) Gil Peck $\left(S^{l} S^{3}\right)$, (c) Van $\left(S^{l} S^{3}\right)$, (d) Bing $\left(S^{3} S^{4}\right)$, (e) Royal Ann $\left(S^{3} S^{4}\right)$, (f) Compact Stella $\left(S^{3} S^{4 m}\right)$, (g) Velvet $\left(S^{2} S^{3}\right)$, (h) Victor $\left(S^{2} S^{3}\right)$, (i) Sue $\left(S^{2} S^{3}\right)$, (j) Governer Wood $\left(S^{3} S^{6}\right)$, (k) Nanyo $\left(S^{3} S^{6}\right)$, (1) Satonishiki $\left(S^{3} S^{6}\right)$, (m) Burlat $\left(S^{3} S^{5}\right)$, (n) Moreau $\left(S^{3} S^{5}\right)$, (o) Peggy Rivers $\left(S^{2} S^{x}\right)$, (p) Rainier $\left(S^{l} S^{4}\right)$.

though the C2-C5 fragments of the cDNAs seemed to crosshybridize to all of the $S$-alleles, exactly the same hybridization signals were obtained with the $\mathrm{C} 2-\mathrm{C} 5$ probes from all the $S$-alleles tested. Furthermore, only one or two bands could be seen with any of the cultivars tested and each $S$-allele could be assigned to one of the bands observed on the blot (Fig. 7), suggesting that the cDNAs were associated with $S$-alleles of sweet cherry. The combined evidence suggests that the cDNAs encode $S$-RNases, and thus the corresponding glycoproteins observed in 2D-PAGE are $S$-RNases of sweet cherry.

It is interesting that two spots other than the $S^{2}$ or $S^{6}$-spots were observed in $S^{2} S^{3}$ and $S^{3} S^{6}$ cultivars. Two different $S$-alleles were present in each cultivar and there should have been two spots, or only one if two different $S$-glycoproteins overlapped on the 2DPAGE gel. The most reasonable explanation is that one of the spots is the $S^{3}$-allelic product and the other is a non-S-protein. However, N-terminal sequencing suggested that both of them could be $S^{3}$-allelic products since the molecules differed only at the N-terminal (Fig. 4). It is possible that signal peptidase cleaved the $S^{3}$-precursor protein at two different positions and consequently two different mature proteins were produced. The observation that the spots with Asp (acidic amino acid) and Gly (neutral amino acid) at the $\mathrm{N}$-terminal (the spots $\mathrm{A}$ and $\mathrm{A}^{\prime}$ ) were located at a more acidic position on the 2D-PAGE gel as compared to the spots without them (the spots B and $\mathrm{B}^{\prime}$ ), is consistent with the hypothesis that only the N-terminal of the two proteins is different and the rest is the same. Furthermore, the fact that only cDNAs encoding the putative $S^{3}$-protein with DG at the N-terminal could be obtained from the cDNA library of 'Satonishiki' and also from 3'RACE clones of 'Satonishiki' and 'Velvet', may support the hypothesis that both two spots were $S^{3}$-allelic products. Ishimizu et al. (1996) suggested that the signal peptidase in Japanese pear style favored nonpolar side chains at the site of action in the propeptidemature protein junction, which conforms to the $(-3,-1)$-rule (von Heijine, 1986). The amino acid sequence around the N-terminal of the mature protein is SAGDGSY and both the Gly-Asp and Gly-Ser bonds could be cleaved without breaking the rule (Fig. 5).

In this study, a practical method of the PCR-based $S$-allele typing system for the six $S$-alleles of sweet cherry cultivars was described. Although the six $S$-alleles could be distinguished from each other by genomic DNA blot analysis (Fig. 7), the PCR-based typing system was developed because PCR analysis is much simpler than genomic DNA blot analysis and considered to be more practical. It appeared that two PCRs were sufficient to distinguish all six $S$-alleles tested (Fig. 8). The six $S$-RNase genes of sweet cherry cultivars seemed to contain introns with different lengths at different positions of the genes. Recently, Boskovic and Tobutt (1997) proposed possible existence of five new $S$-alleles, $S^{7}$ to $S^{11}$, in sweet cherry. If $11 S$-alleles exist, there should be 55 incompatibility groups. Molecular typing systems of $S$-alleles developed in this study based on PCR as well as genomic DNA blot analysis would facilitate identification of new $S$-alleles and incompatibility groups. Although $S^{4 m}$-allele of 'Compact Stella' yielded the same band as the $S^{4}$-allele of other cultivars, it should be possible to select self-compatible offsprings of 'Compact Stella' because there is a very tight genetic linkage between the pollen and stylar part genes for self-incompatibility. For example, offsprings yielded the $S^{4 m}$-band from $S^{1} S^{2} \times S^{3} S^{4 m}$ should be selfcompatible. Also, even though $S^{4 m}$ and $S^{4}$-bands cannot be discriminated, offsprings yielded both $S^{1}$ and $S^{4 m}$-bands from $S^{1} S^{4} \times$ $S^{2} S^{4 m}$ should be self-compatible.

This study clearly demonstrates that $S$-RNase is likely to be involved in gametophytic self-incompatibility of sweet cherry and provides information about cDNA sequences encoding $S$-RNases of this plant species. Furthermore, the cDNAs obtained in this study should be able to be used to produce self-compatible transformants of sweet cherries through the antisense RNA technology such as antisense expression of cDNAs associated with self-incompatibility in Solanaceae (Lee et al., 1994; Murfett et al., 1995).

\section{Literature Cited}

Anderson, M.A., E.C. Cornish, S-L. Mau, E.G. Williams, R. Hoggart, A. Atkinson, I. Bönig, B. Grego, R. Simpson, P.J. Roche, J.D. Haley, J.D. Penschow, H.D. Niall, G.W. Tregear, J.P. Coghlan, R.J. Crawford, and A.E. Clarke. 1986. Cloning of cDNA for a stylar glycoprotein associated with expression of self-incompatibility in Nicotiana alata. Nature 321:38-44.

Boskovic, R., K. Russell, and K.R. Tobutt. 1997. Inheritance of stylar ribonucleases in cherry progenies, and reassignment of incompatibility alleles to two incompatibility groups. Euphytica 95:221-228.

Boskovic, R. and K.R. Tobutt. 1996. Correlation of stylar ribonuclease zymograms with incompatibility alleles in sweet cherry. Euphytica 90:245-250.

Coleman, C.E. and T-H. Kao. 1992. The flanking regions of two Petunia inflata $\mathrm{S}$ alleles are heterogeneous and contain repetitive sequences. Plant Mol. Biol. 18:725-737.

Doyle J.I. and J.L. Doyle. 1987. A rapid DNA isolation procedure for small quantities of fresh leaf tissue. Phytochem. Bul. 19:11-15.

Hiratsuka, S. and N. Hirata. 1985. Self-incompatibility reaction of Japanese pear in various stages of floral development. J. Jpn. Soc. Hort. Sci. 54:9-14.

Horiuchi, H., K. Yanai, M. Takagi, K. Yano, E. Wakabayashi, A. Sanda, S. Mine, K. Ohgi, and M. Irie. 1988. Primary structure of a base nonspecific ribonuclease from Rhizopus niveus. J. Biochem. 103:408-409. Huang, S., H-S. Lee, B. Karunandaa, and T-H. Kao. 1994. Ribonuclease 
activity of Petunia inflata $S$ proteins is essential for rejection of selfpollen. Plant Cell 6:1021-1028.

Ioerger, T.R., A.G. Clark, and T-H. Kao. 1990. Polymorphism at the selfincompatibility locus in Solanaceae predates speciation. Proc. Natl. Acad. Sci. USA 87:9732-9735.

Ishimizu, T., Y. Sato, T. Saito, Y. Yoshimura, S. Norioka, T. Norioka, and F. Sakiyama. 1996. Identification and partial amino acid sequences of seven $S$-RNases associated with self-incompatibility of Japanese pear, Pyrus pyrifolia Nakai. J. Biochem. 120:326-334.

Janssens, G.H., I.L. Goderis, W.F. Broekaert, and W. Broothaerts. 1995. A molecular method for $S$-allele identification in apple based on allelespecific PCR. Theor. Appl. Genet. 91:691-698.

Kaufmann, H., F. Salamini, and R.D. Thompson. 1991. Sequence variability and gene structure at the self-incompatibility locus of Solanum tuberosum. Mol. Gen. Genet. 226:457-466.

Kawata, Y., F. Sakiyama, and H. Tamaoki. 1988. Amino-acid sequence of ribonuclease T2 from Aspergillus oryzae. Eur. J. Biochem. 176:683697.

Kheyr-Pour, A., S.B. Bintrim, T.R. Ioerger, R. Remy, S.A. Hammond, and T-H. Kao. 1990. Sequence diversity of pisitil S-proteins associated with gametophytic self-incompatibility in Nicotiana alata. Sex. Plant Reprod. 3:88-97.

Knight, R.L. 1969. Abstract bibliography of plant breeding and genetics to 1965 in Prunus. Eastern Press, London.

Lapins, K.O. 1970. The Stella cherry. Fruit Var. Hort. Dig. 24:19-20.

Lapins, K.O. 1975. 'Compact Stella' cherry. Fruit Var. J. 29:20-21.

Lee, H-S., S. Huang, and T-H. Kao. 1994. S proteins control rejection of incompatible pollen in Petunia inflata. Nature 367:560-563.

Mak, Y-M. and K-K. Ho. 1993. Use of polyethylene glycol for purification of DNA from leaf tissue of woody plants. BioTechniques 14:735736.

McClure, B.A., J.E. Gray, M.A. Anderson, and A.E. Clarke. 1990. Selfincompatibility in Nicotina alata involves degradation of pollen rRNA. Nature 347:757-760.

McClure, B.A., V. Haring, P.R. Ebert, M.A. Anderson, R.J. Simpson, F. Sakiyama, and A.E. Clarke. 1989. Style self-incompatibility gene products of Nicotiana alata are ribonucleases. Nature 342:955-957.

Murfett, J., T.L. Atherton, B. Mou, C.S. Gasser, and B.A. McClure. 1994. $S$-RNase expressed in transgenic Nicotiana causes $S$-allele-specific pollen rejection. Nature 367:563-566.

Murfett, J., J.E. Burque, and B.A. McClure. 1995. Antisense suppression of S-RNase expression in Nicotiana using RNA polymerase II- and IIItranscribed gene constructs. Plant Mol. Biol. 29:201-212.

de Nettancourt, D. 1977. Incompatibility in angiosperms. SpringerVerlag, Berlin.
Norioka, N., S. Norioka, Y. Ohnishi, T. Ishimizu, C. Oneyama, T. Nakanishi, and Sakiyama, F. 1996. Molecular cloning and nucleotide sequences of cDNAs encoding $S$-allele specific stylar RNases in a selfincompatible cultivar and its self-compatible mutant of Japanese pear, Pyrus pyrifolia Nakai. J. Biochem. 120:335-345.

Pimienta, E., V.S. Polito, and D.E. Kester. 1983. Pollen tube growth in cross- and self-pollinated 'Nonpareil' almond. J. Amer. Soc. Hort. Sci. 108:643-647.

Raff, J.W., J.M. Pettitt, and R.B. Knox. 1982. Cytochemistry of pollen tube growth in stigma and style of Prunus avium. Phytomorphology 31:214-231.

Royo, J., Y. Kowyama, and A.E. Clarke.1994. Cloning and nucleotide sequences of two $S$-RNases from Lycopersicon peruvianum. Plant Physiol. 105:751-752.

Sassa, H. and H. Hirano. 1997. Nucleotide sequence of a cDNA encoding S5-RNase (Accession No. D88282) from Japanese pear (Pyrus serotina). Plant Physiol. 113:306.

Sassa, H., H. Hirano, and H. Ikehashi. 1993. Identification and characterization of stylar glycoproteins associated with self-incompatibility genes of Japanese pear, Pyrus serotina Rehd. Mol. Gen. Genet. 241:17-25.

Sassa, H., T. Nishio, Y. Kowyama, H. Hirano, T. Koba, and H. Ikehashi. 1996. Self-incompatibility $(S)$ alleles of the Rosaceae encode members of a distinct class of the $\mathrm{T}_{2} / \mathrm{S}$ ribonuclease superfamily. Mol. Gen. Genet. 250:547-557.

Tao, R., H. Yamane, H. Sassa, H. Mori, T.M. Gradziel, A.M. Dandekar, and A. Sugiura. 1997. Identification of stylar RNases associated with gametophytic self-incompatibility in almond (Prunus dulcis). Plant Cell Physiol. 38:304-311.

Tehrani, G. and S.K. Brown. 1992. Pollen-incompatibility and selffertility in sweet cherry. Plant Breed. Rev. 9:313-338.

Thompson, J.D., D.G. Higgins, and T.J. Gibson. 1994. CLUSTAL W: Improving the sensitivity of progressive multiple sequence alignment through sequence weighting, positions-specific gap penalties and weight matrix choice. Nucleic Acids Res. 22:4673-4680.

Tomimoto, Y., T. Nakazaki, H. Ikehashi, H. Ueno, and R. Hayashi. 1996. Analysis of self incompatibility-related ribonucleases ( $S$-RNases) in two species of pears, Pyrus communis and P. Ussuriensis. Scientia Hort. 66:159-167.

Tsai, D-S., H-S. Lee, L.C. Post, K.M. Kreiling, and T-H. Kao. 1992. Sequence of an $S$-protein of Lycopersicon peruvianum and comparison with other solanaceous $S$-proteins. Sex. Plant Reprod. 5:256-263.

von Heijne, G. 1986. A new method for predicting signal sequence cleavage site. Nucleic Acids Res. 14:4683-4690.

Xue, Y., R. Carpenter, H.G. Dickinson, and E.S. Coen. 1996. Origin of alleic diversity in Antirrhinum $S$ locus RNases. Plant Cell 8:805-814. 